\title{
Response of Variant Hereditary Angioedema Phenotypes to Danazol Therapy
}

\author{
GENETIC IMPLICATIONS
}

\author{
James E. Gadek, Stephen W. Hosea, JefFrey A. Gelfand, and Michael M. Frank, \\ Laboratory of Clinical Investigation, National Institute of Allergy and Infectious \\ Diseases, National Institutes of Health, Bethesda, Maryland 20014
}

\begin{abstract}
A B S T R A C T Hereditary angioedema (HAE), an autosomal dominant disorder characterized by attacks of episodic edema is associated with decreased functional levels of the $\mathrm{Cl}$ esterase inhibitor. Approximately $85 \%$ of patients have lowered antigen levels of a normal inhibitor protein. $15 \%$ of patients have normal or elevated antigenic levels of functionless protein. We have examined the response to danazol therapy of patients with the variant HAE phenotypes possessing the abnormal protein in an effort to determine if these patients possess a normal structural C1 inhibitor allele. Four patients with a variant HAE phenotype were treated successfully with danazol. In two patients, distinguished by the presence of a functionless, albumin-bound, $\mathrm{Cl}$ inhibitor (phenotype 2), phenotypic analysis of the danazol response by bidirectional immunoelectrophoresis revealed the appearance of the normal $\mathrm{Cl}$ inhibitor gene product during danazol therapy. This relatively cathodal $\mathrm{Cl}$ inhibitor peak appears in conjunction with the development of nearly normal functional activity. All of the functional $\mathrm{Cl}$ inhibitory activity which appeared in the phenotype 2 treatment serum was associated with the electrophoretically normal inhibitor. This normal protein could be separated from the functionless inhibitor protein by immunoadsorption and molecular sieve
\end{abstract}

This work was presented in part at the Scientific Session of the American Federation for Clinical Research, Washington, D. C., May 1977.

Dr. Gadek's present address is Pulmonary Branch, National Heart, Lung, and Blood Institute, National Institutes of Health, Bethesda, Md. 20014; Dr. Hosea's present address is Department of Internal Medicine, Infectious Diseases Section, Yale University School of Medicine, New Haven, Conn. 06510; and Dr. Gelfand's present address is Department of Medicine, New England Medical Center Hospital, Boston, Mass. 02111.

Received for publication 12 October 1978 and in revised form 19 March 1979. chromatography. Danazol therapy of the two patients with an electrophoretically normal, functionless $\mathrm{Cl}$ inhibitor (phenotype 3) also resulted in a clinical remission associated with development of a significant increment in functional serum $\mathrm{Cl}$ inhibitory activity and $\mathrm{Cl}$ inhibitor protein. These findings demonstrate that these two HAE phenotypic variants are heterozygous for the normal serum $\mathrm{Cl}$ inhibitor, a finding which was not apparent before phenotypic analysis of this serum during danazol therapy. These data provide strong evidence for a basic similarity between the common form of HAE and its phenotypic variants. They also suggest that a structural gene lesion may result in the abnormalities of serum $\mathrm{Cl}$ inhibitor function and disease expression in all three of these HAE phenotypes.

\section{INTRODUCTION}

Hereditary angioedema (HAE) ${ }^{1}$ is a clinical syndrome characterized by episodic swelling which can involve any external portion of the body, the upper airway, or the bowel wall (1). The disease has an autosomal dominant inheritance pattern which has been clearly recognized since its description by Osler in 1888 (2). Disease expression is associated with deficiency of the serum inhibitor of the activated complement enzyme, $\mathrm{Cl}$ esterase (3). When present at normal serum levels, the $\mathrm{Cl}$ inhibitor ( $\mathrm{Cl} \mathrm{Inh}$ ) modulates the early events of the classical complement sequence. When the $\mathrm{Cl}$ proenzyme is activated and acquires esterase activity (4), C1 Inh binds stoichiometrically and irreversibly to the esterolytic site and thus prevents further activation of the complement cascade (5). Current evidence suggests that a loss of this regulatory function, as seen in $\mathrm{HAE}$, permits excessive cleavage of $\mathrm{C} 4$ and $\mathrm{C} 2$ by $\mathrm{C} 1$

\footnotetext{
${ }^{1}$ Abbreviations used in this paper: $\mathrm{Cl} \mathrm{Inh}, \mathrm{Cl}$ inhibitor; HAE, hereditary angioedema.
} 
esterase with the resultant generation of a kinin-like fragment from C2 (6). In HAE patients it may be this kinin-like product of unchecked $\mathrm{Cl}$ esterase activity which produces the characteristic, nonpruritic angioedema.

The majority of HAE patients demonstrate a deficiency of both antigenic and functional serum $\mathrm{Cl}$ Inh activity. However, some $15-20 \%$ of patients possess normal or elevated levels of antigenic $\mathrm{Cl}$ Inh which is deficient in functional activity (7-9). In spite of the presence of functionless $\mathrm{Cl}$ Inh proteins in this subset of HAE patients, when a family history of HAE exists, these variant phenotypes demonstrate the same autosomal dominant inheritance pattern and clinical expression of C1 Inh deficiency seen in the common phenotype (8). This phenotypic heterogeneity is further exemplified by the fact that although the common phenotype appears to be heterozygous for the functional $\mathrm{Cl}$ Inh (that is, some normally functioning protein is present), the presence of the normal $\mathrm{Cl}$ Inh gene product has not been demonstrated in those phenotypes distinguished by the presence of the inactive inhibitors. The existence of these inert, $\mathrm{Cl}$ Inh proteins and the inability to demonstrate that these patients are heterozygous for the normal protein has introduced a formidable obstacle to development of a unifying genetic scheme that encompasses the entire syndrome.

Spaulding (10) first showed the efficacy of androgen therapy in HAE by demonstrating a significant decrease in disease activity during continuous methyltestosterone therapy. Subsequently, androgens with lesser virilizing potential were shown to control HAE (11). Recent studies with the ethinyltestosterone derivative, danazol, have demonstrated that this agent provides effective prophylaxis in nearly all HAE patients (12). Control of the clinical syndrome with danazol is associated with correction of the biochemical manifestations of HAE. In those patients with the common phenotype (reduced $\mathrm{Cl}$ Inh antigen and function) danazol therapy resulted in a mean 3.5-fold increase in the serum $\mathrm{Cl}$ Inh antigen, and the development of near normal functional inhibitor activity. In normal individuals as well, danazol causes a significant increase in the serum C1 Inh level (12).

In the present study we have analyzed the biochemical response to danazol therapy in four patients who possess the functionless $\mathrm{Cl}$ Inh proteins. Two of these patients (phenotype 2) possess a functionless $\mathrm{Cl}$ Inh which is bound to serum albumin in a 1:1 molar ratio and has an electrophoretic mobility which exceeds that of the normal protein $(8,9)$. The other two subjects (phenotype 3 ) are characterized by the presence of a functionless $\mathrm{Cl}$ Inh protein with an electrophoretic mobility in agarose which is identical to the normal protein (8). The distinctive physicochemical characteristics of the albumin-bound inhibitor in phenotype 2 provide a convenient marker for the nonfunctioning $\mathrm{Cl}$ Inh protein, the product of the affected $\mathrm{Cl}$ Inh allele. The biochemical response of these patients to danazol therapy was analyzed in an effort to clarify some of the genetic principles operative in this inherited serum protein deficiency.

\section{METHODS}

C1 inhibitor levels. Antigenic C1 Inh levels were measured in serum samples by a standard radial immunodiffusion method. Monospecific anti-C1 Inh was raised in rabbits by repeated footpad injections of purified protein (13) in Freund's complete adjuvant. This anti-Cl Inh antiserum was monospecific as demonstrated by the presence of a single precipitin arc on immunoelectrophoretic analysis of normal human serum. The anti-Cl Inh produced a line of identity between normal human serum and highly purified $\mathrm{Cl}$ Inh. The monospecific anti-Cl Inh antiserum was added to $0.75 \%$ agarose in Veronal acetate buffer $(\mathrm{pH} \mathrm{8.0,0.1} \mathrm{M)} \mathrm{in} \mathrm{amounts}$ found optimal for formation of precipitin rings.

Functional $\mathrm{Cl}$ Inh activity was assayed in serum samples employing a modification of the method of Gigli et al. (14) which measures the inhibition of hemolytic $\mathrm{Cl}$ esterase activity. The assay was altered to simplify the handling of the serum to be assayed and to effect a more complete removal of endogenous $\mathrm{Cl}$ esterase from the serum sample. Sera were first mixed with $20 \%$ polyethylene glycol (Carbowax 4000 , Fisher Scientific Co., Pittsburgh, Pa.) at $0^{\circ} \mathrm{C}$ for $30 \mathrm{~min}$. After centrifugation and removal of the precipitate, the $20 \%$ polyethylene glycol supernate was again treated to bring the final polyethylene glycol content to $40 \%$ (wt/vol). Precipitation of serum was allowed to proceed at $0^{\circ} \mathrm{C}$ for $30 \mathrm{~min}$ and the serum was then centrifuged. This supernate was discarded and the precipitate was resuspended in the original serum volume in phosphate-buffered saline $(\mathrm{pH} 7.4 ; 0.15 \mathrm{M})$. The dissolved precipitate contained all the $\mathrm{Cl}$ Inh protein present in the starting serum and was devoid of detectable $\mathrm{Cl}$ esterase activity. The $\mathrm{Cl}$ Inh titers obtained using this polyethylene glycol precipitation did not differ from those obtained on the same samples using Gigli's method which requires precipitation of endogenous $\mathrm{Cl}$ esterase by acidification and dilution of the starting serum. In later experiments the technique was further simplified by omission of the $40 \%$ precipitation with polyethylene glycol since it was found that assay of the $20 \%$ supernate resulted in the same $\mathrm{Cl}$ inhibitory titer as did assay of the solubilized $40 \%$ precipitate. Functional C1 Inh activity was measured as the reciprocal of that serum dilution which produced inhibition of one hemolytic $\mathrm{Cl}$ esterase site per sheep erythrocyte and is expressed as the percentage of a standard control serum activity.

Immunoadsorbant preparation. An anti-Cl Inh immunoadsorbant was prepared by the insolubilization of monospecific rabbit antiserum in $2.5 \%$ glutaraldehyde (15). The antialbumin antiserum was prepared by injection of chromatographically purified human albumin (Behring Diagnostics, American Hoechst Corp., Somerville, N. J.), in complete Freund's adjuvant, into the footpads of rabbits. This antiserum was shown to be monospecific for human albumin by tandem, bidirectional immunoelectrophoresis of normal human serum and purified albumin in agarose. The immunoglobulin (Ig)G fraction of this monospecific antialbumin serum was isolated by caprylic acid precipitation (16). An antialbumin immunoadsorbant was prepared by coupling this IgG fraction to cyanogen bromide-(Eastman Organic Chemicals Div., Eastman Kodak Co., Rochester, N. Y.) activated Sepharose 4B 
(Pharmacia Fine Chemicals, Div. of Pharmacia Inc., Piscataway, N. J.). A single passage of normal serum over this antialbumin immunoadsorbant resulted in removal of $80 \%$ of the albumin content without measurable reduction in the normal serum $\mathrm{Cl}$ Inh antigen or function.

All immunoadsorptions of serum were carried out at $4^{\circ} \mathrm{C}$ for $60 \mathrm{~min}$.

Molecular sieve chromatography. Gel filtration on Sephadex G-200 (Pharmacia Fine Chemicals) was one method used to analyze the relationship of the albumin-bound $\mathrm{Cl}$ Inh of $\mathrm{HAE}$ phenotype 2 to the functional $\mathrm{Cl}$ Inh activity generated during danazol therapy. To facilitate the functional $\mathrm{Cl}$ Inh assay of the elution fractions, the total $\mathrm{Cl}$ Inh fraction of serum obtained during danazol therapy was concentrated before chromatography by means of polyethylene glycol precipitation. Polyethylene glycol was added to $100 \mathrm{~cm}^{3}$ of the serum to achieve a final concentration of $20 \% \mathrm{wt} / \mathrm{vol}$. The serum was permitted to stand at $0^{\circ} \mathrm{C}$ for $30 \mathrm{~min}$ and then centrifuged to remove the precipitate. An additional $20 \%$ polyethylene glycol was then added to the supernate to produce a final concentration of $40 \%$. The suspension was then permitted to stand at $0^{\circ} \mathrm{C}$ for $30 \mathrm{~min}$ and again centrifuged after which the supernate was discarded. The $20-40 \%$ precipitate was then resuspended in cold $\left(4^{\circ} \mathrm{C}\right)$ phosphate-buffered saline ( $\mathrm{pH} \mathrm{7.4)} \mathrm{to} \mathrm{a} \mathrm{volume} \mathrm{of} 25 \mathrm{~cm}^{3}$. This $25-\mathrm{cm}^{3}$ sample was then applied to a $5 \times 100-\mathrm{cm}$ Sephadex G-200 bed equilibrated in the same buffer. The concentrated sample contained all the $\mathrm{Cl}$ Inh protein present in the original serum. This maneuver permitted a fourfold concentration of the $\mathrm{Cl}$ Inh antigen and functional activity and facilitated the functional assay of the G-200 eluate.

Bidirectional immunoelectrophoresis. Bidirectional or crossed immunoelectrophoresis (17) was used to analyze the serum of HAE patients to identify the phenotypic Cl Inh pattern and characterize the alterations of this pattern during danazol therapy. Sera were concentrated threefold by a $20-$ $40 \%$ polyethylene glycol precipitation as outlined earlier. $6 \mu$ l of the concentrate was added to wells formed in $0.75 \%$ agarose. Electrophoresis in a standard cell (NIH Instrument Shop, Bethesda, Md.) was carried out in the first dimension for $120 \mathrm{~min}$ at $30 \mathrm{mV}$ with the temperature maintained at $10^{\circ} \mathrm{C}$. The agarose strips were then carefully removed from the electrophoretic plate and fitted to an agarose slab containing the quantity of anti-Cl Inh IgG found optimal for the formation of precipitin rockets. Electrophoresis was allowed to proceed at right angles to the first electrophoretic field permitting the $\mathrm{Cl}$ Inh to migrate into the antibody-containing gel. The second electrophoresis was run at $30 \mathrm{mV}$ for $120 \mathrm{~min}$ at $10^{\circ} \mathrm{C}$. All electrophoresis was performed at $\mathrm{pH}$ 8.0-8.2 in Veronal acetate $(0.1 \mathrm{M})$ buffer.

\section{RESULTS}

The clinical response of the four patients with functionless inhibitors was indistinguishable from that of the patients with the common phenotype. Effective control of HAE attacks was achieved in each of these subjects. The bidirectional immunoelectrophoretic analysis of HAE phenotypes 2 and 3 are represented in Fig. 1. Cl Inh levels in phenotype 2 serum increased from 35 to $48 \mathrm{mg} / \mathrm{dl}$ during danazol therapy. The electrophoretic pattern demonstrates an $\cong 2.5$-fold increase in the minor cathodal $\mathrm{C} 1 \mathrm{Inh}$ peak noted on the initial electrophoresis. In another patient a 4.5-fold increase in the minor peak was noted. Associated with this in-

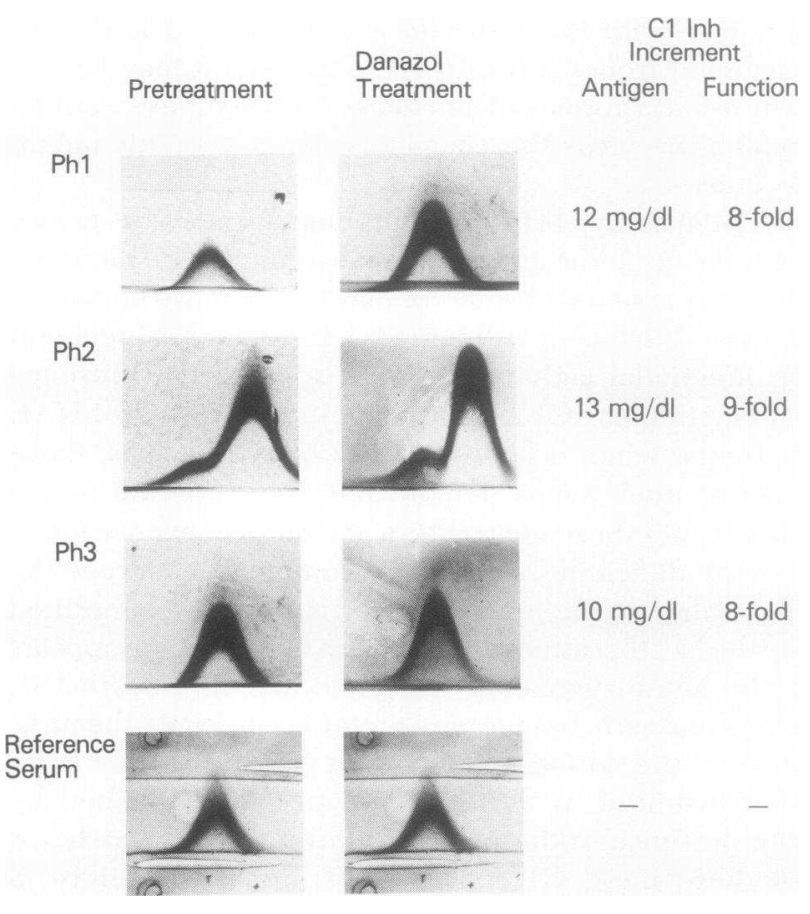

FIGURE 1 Bidirectional immunoelectrophoresis of serum obtained from patients with HAE phenotypes (Ph) 1, 2, and 3 . The electrophoretic patterns were analyzed before and $14 \mathrm{~d}$ after initiation of therapy with $600 \mathrm{mg}$ of danazol q.d. The increment in serum $\mathrm{Cl}$ Inh antigenic and functional activity achieved during danazol therapy was determined for each of the three phenotypes. The fourth pattern represents the immunoelectrophoretic mobility of the $\mathrm{Cl} \mathrm{Inh}$ in normal serum. Electrophoresis was performed at $\mathrm{pH} 8.6$ in $0.75 \%$ agarose; the anode is on the right.

crease in the minor peak was the appearance of $\mathrm{Cl} \mathrm{Inh}$ functional activity which reached $90 \%$ of the normal level.

Danazol therapy of HAE phenotype 3 resulted in an increase in $\mathrm{Cl}$ Inh antigen from 30 to $40 \mathrm{mg} / \mathrm{dl}$. The electrophoretic analysis of this $\mathrm{Cl}$ Inh increment revealed an increase in the single $\mathrm{Cl}$ Inh peak whose mobility was identical to that of the normal reference protein. Again the observed clinical remission and augmentation of the $\mathrm{Cl}$ Inh protein level was associated with the appearance of near normal inhibitory function.

To clarify the nature of danazol's effect in these variant phenotypes, advantage was taken of the distinct biochemical properties of the functionless inhibitor in HAE phenotype 2.

Anti-C1 Inh immunoadsorption. This experiment was designed to evaluate the specificity of the increased $\mathrm{C} 1$ Inh functional activity in these variant phenotypes. To exclude the possibility that the increased serum $\mathrm{Cl}$ esterase inhibitory activity resulted from augmentation of serum protease inhibitors other than the $\mathrm{Cl}$ Inh, a monospecific anti-Cl Inh immunoadsorbant was used to deplete the danazol-treated serum of its $\mathrm{Cl}$ Inh 
protein. This adsorption resulted in a decrease of the $\mathrm{Cl}$ Inh protein from 45 to $3 \mathrm{mg} / \mathrm{dl}$ in phenotype 2 serum as seen in Fig. 2. This process removed the entirety of the serum's functional activity. Thus, all the measured $\mathrm{C} 1 \mathrm{Inh}$ function generated during danazol therapy was attributable to the $\mathrm{Cl}$ Inh protein and was not due to the presence of other protease inhibitors. This anti-Cl Inh immunoadsorbant also removed all the detectable $\mathrm{Cl}$ Inh antigen and function which had been generated in HAE phenotype 1 serum during danazol therapy (data not shown).

Immunoadsorption of albumin-bound C1 Inh. Fig. 3 demonstrates the selective removal of the anodal, $\alpha 1 \mathrm{Cl}$ Inh from phenotype 2 treatment serum by adsorption with a monospecific, Sepharose-bound antialbumin. The immunoadsorption of the albumin-bound Cl Inh species produced a decrease in the serum's C1 Inh content from 45 to $13 \mathrm{mg} / \mathrm{dl}$. The crossed immunoelectrophoretic pattern of the adsorbed serum confirmed that the residual $\mathrm{Cl}$ Inh antigen was found in the cathodal inhibitor peak whose mobility was near that of the normal, $\alpha 2$ protein. In contrast to the results obtained in the anti-Cl Inh adsorption, the removal of the $\alpha \mathrm{l} \mathrm{Cl}$ Inh protein was not associated with a significant reduction of the serum's functional activity. Thus, the albumin-bound $\mathrm{Cl}$ Inh peak accounted for none of the serum's inhibitory function. The newly appearing functional activity was associated entirely with the $\alpha 2$ inhibitor species.

Passage of HAE phenotype 2 serum (obtained during danazol therapy) over control Sepharose 4B columns resulted in loss of neither albumin nor $\mathrm{Cl}$ Inh antigen and inhibitor function (data not shown).

Molecular sieve chromatography of HAE phenotype 2 serum during danazol therapy. Confirmation of the association of functional $\mathrm{Cl}$ Inh activity with the cathodal C1 Inh species in phenotype 2 treatment serum was obtained by gel filtration. The $\alpha 1$ albumin-C1 Inh complex has an approximate $150,000 \mathrm{~mol}$ wt which permits its separation by molecular sieve chromatography from the unbound, cathodal inhibitor. Phenotype 2 serum, whose functional activity was increased to the normal range during danazol therapy,

\begin{tabular}{|c|c|c|}
\hline & $\begin{array}{c}\text { CIm by } \\
\text { Redial Immunodithusion } \\
\text { mg/d }\end{array}$ & 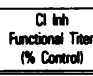 \\
\hline Pretreatment Serum & 35 & 9 \\
\hline Danazol Treatment Serum & 45 & 90 \\
\hline $\begin{array}{l}\text { Danazol Treatment/Adsorbed } \\
\text { Serum/Ant }\end{array}$ & 3 & 0 \\
\hline
\end{tabular}

FIGURE 2 Immunoadsorption of $\mathrm{Cl}$ Inh protein in serum obtained from a patient with HAE phenotype $(\mathrm{Ph}) 2$ during danazol therapy. Total $\mathrm{Cl}$ Inh protein and the functional $\mathrm{Cl}$ Inh titer (expressed as percent of control) were determined before and after danazol therapy and after anti-Cl Inh immunoadsorption.

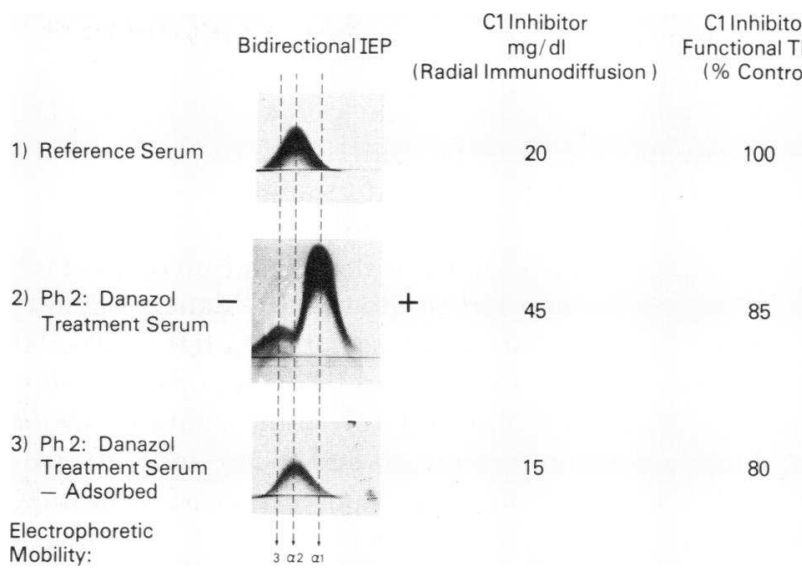

FIGURE 3 Immunoadsorption of albumin-bound $\mathrm{Cl}$ Inh in serum obtained from HAE phenotype $(\mathrm{Ph}) 2$ patient during danazol therapy. Interrupted lines depict the electrophoretic mobilities $(3, \alpha 2, \alpha 1)$ of the $\mathrm{Cl}$ Inh species present in normal reference serum and the $\mathrm{Ph} 2$ serum before and after antialbumin adsorption. The total $\mathrm{Cl}$ Inh content and functional Cl Inh titer (expressed as percent of control serum) were determined for each of these sera.

was concentrated by polyethylene glycol precipitation. The $20-40 \%$ polyethylene glycol serum precipitate was resuspended to one-third the original volume and chromatographed on a Sephadex G-200 column. The first Cl Inh species to elute from this column was the heavier, $\alpha 1$ protein. In those fractions containing this albumin-bound $\mathrm{Cl}$ Inh alone, there was no functional activity (Fig. 4). As the elution profile evolved, there

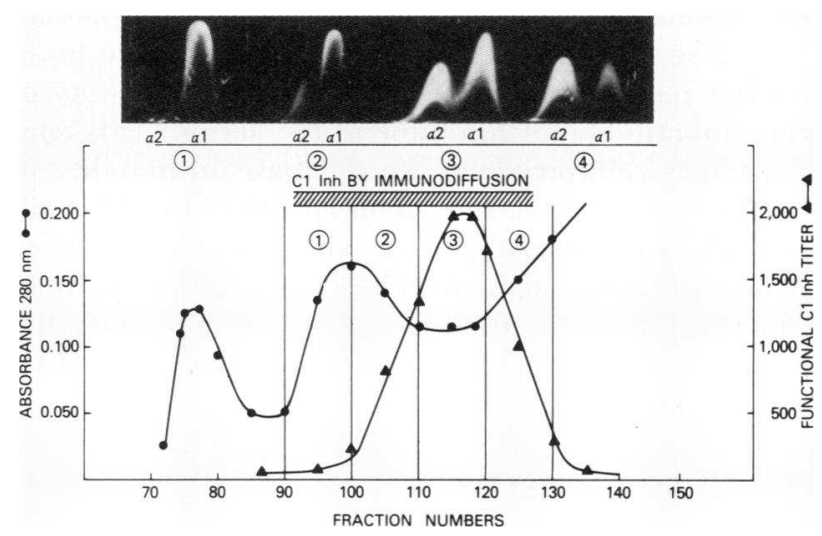

FIGURE 4 Gel filtration chromatography of serum obtained from a patient with HAE phenotype 2 during danazol therapy. The elution profile for the two species of $\mathrm{C} 1$ Inh protein $(\alpha 2$, $\alpha 1$ ) is represented by the electrophoretic patterns designated 1 through 4 corresponding to the numbered portions of the chromatographic run. Fractions 92 through 128 contained all the eluted $\mathrm{Cl}$ Inh antigen as determined by immunodiffusion. The elution of functional $\mathrm{Cl}$ Inh activity is plotted on the right ordinate $(\boldsymbol{\Delta})$ as the reciprocal of the sample dilution that inhibited one hemolytic $\mathrm{Cl}$ esterase site. The protein content is plotted on the left ordinate as absorbance at $280 \mathrm{~nm}(\odot)$. 
was a stepwise decrease in the contribution of the $\alpha 1$, albumin-bound $\mathrm{Cl}$ Inh species to the electrophoretic pattern whereas the $\alpha 2$ peak increased reciprocally. Assay of the fractions for functional $\mathrm{Cl}$ Inh activity demonstrated that inhibitory function eluted with the smaller $(90,000 \mathrm{~mol} \mathrm{wt}), \alpha 2$ inhibitor species. Thus, both immunologic and physical segregation of the $2 \mathrm{Cl}$ Inh species served to illustrate that the danazol-generated functional activity was associated with the cathodal $\mathrm{Cl}$ Inh peak in phenotype 2 . Addition of purified serum albumin to the unbound $\mathrm{Cl}$ Inh after separation from its functionless counterpart failed to produce electrophoretic or functional alteration of this $\alpha 2$ inhibitor. Furthermore, addition of purified, normal C1 Inh protein to untreated phenotype 2 serum resulted in appearance of a cathodal inhibitor peak of the same mobility observed for the peak which appeared during danazol therapy. The purified $\mathrm{Cl}$ Inh, when added to phenotype 2 serum, demonstrated no equilibrium with the $\alpha 1$ peak through albumin binding, and possessed a mobility slightly cathodal of the normal reference protein (data not shown).

Interpretation of the crossed immunoelectrophoretic analysis of the phenotype 2 response to danazol was initially complicated by the slower migration of the newly appearing $\mathrm{C} 1$ Inh peak when referenced to the $\alpha 2 \mathrm{Cl}$ Inh peak in normal serum (Fig. 3). This issue was resolved by the shift of the functional peak's mobility after adsorption of the $\alpha 1$ peak. With removal of the albumin-bound $\mathrm{Cl}$ Inh, the functional $\mathrm{Cl}$ Inh peak assumed a mobility equivalent to that of the normal inhibitor. Presumably, the discrepancy between the mobilities of the functional $\mathrm{Cl}$ Inh peak in phenotype 2 serum and the reference protein is due to an artifact related to the presence of a large quantity of the albumin-bound inhibitor in the serum. This conclusion is reinforced by the decrease in mobility of purified, normal $\mathrm{Cl}$ Inh when added to unadsorbed, pretreatment, phenotype 2 serum. Thus, the control of disease activity and the development of adequate functional $\mathrm{Cl}$ esterase inhibition is associated with the appearance of the normal $\mathrm{Cl}$ Inh gene product in $\mathrm{HAE}$ phenotype 2 .

\section{DISCUSSION}

Previous studies have demonstrated that the functionless $\mathrm{Cl}$ Inh proteins in the variant $\mathrm{HAE}$ phenotypes are physicochemically heterogeneous (8). This heterogeneity has been shown in studies of electrophoretic mobility and in studies of C1-binding activity. It has been suggested that this heterogeneity reflects diversity at the level of the gene lesion itself which distinguishes these phenotypes from the common phenotype with low levels of normally functioning inhibitor. However, the common dominant inheritance pattern, identical clinical expression, and similar response to danazol therapy argue for a basic genetic similarity among the HAE phenotypes. The nature of the response to danazol was analyzed in an attempt to obtain insight into the genetic basis for HAE.

Results of the present study of two HAE variant phenotypes provide evidence of their similarity to the more common form of the disease.

Danazol therapy resulted in the augmentation of $\mathrm{Cl}$ Inh function and antigenic levels in HAE phenotype 1 (12). Similarly, the development of serum Cl inhibitory function in phenotype 2 was associated with the appearance of a relatively cathodal peak of $\mathrm{Cl}$ Inh protein in addition to the nonfunctional, albumin-bound protein. HAE phenotype 3 serum demonstrated an increase in the $\mathrm{Cl}$ Inh peak whose electrophoretic mobility was identical to the normal, $\alpha 2$ protein. The association of normal $\mathrm{Cl}$ Inh function with the cathodal $\mathrm{Cl}$ Inh species in treated HAE phenotype 2 patients was demonstrated by the companion immunoadsorption experiments. In this phenotype, the danazol-induced increment in $\mathrm{Cl}$ Inh function was localized to the unbound, cathodal, $\mathrm{C} 1$ Inh peak. It is probable that the small, cathodal $\mathrm{Cl}$ Inh peak present in the pretreatment phenotype 2 serum represents the normal $\mathrm{Cl}$ Inh gene product. Before therapy, this inhibitor species is present at a serum level approximating that seen in phenotype 1. Since this cathodal "inhibitor" possessed an electrophoretic mobility distinct from the $\mathrm{Cl}$ Inh in normal serum, it was not previously believed to represent the product of a normal allele (8). This issue was clarified during the present study by electrophoretic analysis of the phenotype 2 serum after immunoadsorption of the albumin-bound Cl Inh. Removal of this functionless protein permitted the functional, cathodal inhibitor to assume a normal electrophoretic mobility. The apparent discrepancy between the $\mathrm{Cl}$ Inh in normal serum and the functional protein increased during danazol therapy likely represents an artifact introduced by the presence of the albumin-bound, anodal $\mathrm{Cl}$ Inh in phenotype 2 serum.

Analysis of HAE phenotype 3 during danazol therapy reveals an increase in the pretreatment $\mathrm{Cl}$ Inh peak coincident with the appearance of normal functional activity. Interpretation of the phenotype 3 response, in the context of the phenotype 2 results, suggests that the increase in the $\mathrm{Cl}$ Inh peak represents an augmentation of the normal gene product during danazol therapy, which is obscured by the fact that the functionless protein has a normal electrophoretic mobility.

It is apparent from these studies, that in addition to sharing a common inheritance pattern and clinical syndrome, patients with HAE phenotypes 1,2 , and 3 are all heterozygous for the normal $\mathrm{Cl}$ Inh allele. In 
view of the demonstration of the normal gene product in phenotype 2, the presence of a normal $\mathrm{Cl}$ Inh gene can be deduced in phenotype 3 . Thus, phenotypes 1 , 2 , and 3 differ only in the expression of the defective Cl Inh allele. This scheme is depicted graphically in Fig. 5.

These experiments do not formally disprove the possibility that the abnormal gene product causes feedback inhibition of normal $\mathrm{Cl}$ inhibitor synthesis. However, if such were the case, one would have to postulate different control mechanisms in patients with phenotype 1 as compared with phenotypes 2 and 3 . Such may be the case, however, we prefer a single genetic hypothesis to include all of the HAE phenotypes.

The dominant mode of inheritance seen in HAE is unusual. Most often autosomal serum protein deficiency diseases are expressed only in those individuals who are homozygous for the defect. It would seem that, in most instances, the presence of half of the gene product is sufficient to maintain homeostasis. This would appear to be the case for inherited serum $\alpha \mathrm{l}$ antitrypsin deficiency (i.e., expression of disease occurs only when neither allele is normal) (18). However, the inheritance pattern of another serum proteinase inhibitor deficiency syndrome, antithrombin III deficiency, appears to closely approximate that seen in HAE (19). In an effort to explain the dominant pattern in $\mathrm{HAE}$, a regulatory gene defect has been suggested (20). In this scheme, the defective gene is capable of a negative influence on the normal allele as well as its own product by means of a diffusible repressor substance. Drawing from the work of Jacob and Monod, the regulator gene concept would also provide an explanation for the presence of less than one-half the normal serum $\mathrm{Cl}$ Inh level in affected phenotype 1 heterozygotes. However, such a concept is difficult to reconcile with the existence of the abnormal protein variants. An alternative to the regulator gene defect which encompasses all of the phenotypes can be constructed if it is postulated that the product of a single normal $\mathrm{Cl}$ Inh allele is insuf-

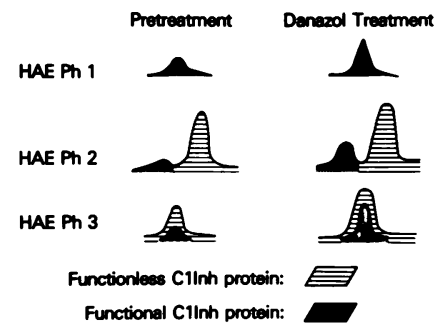

Figure 5 Graphic representation of the relative contributions of functionless and functional $\mathrm{Cl}$ Inh species to the bidirectional immunoelectrophoretic patterns of $\mathrm{Cl}$ Inh in the serum of HAE patients with phenotypes 1,2 , and 3 before and after danazol therapy. ficient to maintain esterase-inhibitor homeostasis. Such a mechanism has been postulated on theoretical grounds (21). This hypothesis presumes that this imbalance and the resultant expression of disease activity can be corrected only when this single $\mathrm{Cl}$ Inh gene is induced to increase its production with an anabolic agent like danazol. In this scheme the serum levels of the functional, $\alpha 2 \mathrm{C} 1 \mathrm{Inh}$ in untreated phenotype 1, 2 , and 3 patients may be less than one-half normal as a result of esterase-inhibitor utilization. Moreover, it may be postulated that elevated levels of the functionless inhibitor proteins result from decreased catabolism because of their inability to interact with $\mathrm{Cl}$. The definitive answer to these issues awaits study of the metabolic turnover of the $\mathrm{Cl}$ Inh protein in HAE patients before and during danazol therapy.

Much of the genetic basis of HAE remains to be clarified. However, demonstration of the normal gene product in phenotype 2 and 3 through analysis of their response to danazol, provides new insight into this problem. In addition to offering the potential for control of disease activity in many HAE patients, including the variant phenotypes, danazol has provided important clues to the basic mechanisms underlying this disease.

\section{ACKNOWLEDGMENT}

The authors wish to thank Dr. Victor A. McKuscick of the Johns Hopkins Hospital for his useful discussions.

\section{REFERENCES}

1. Frank, M. M., J. A. Gelfand, and J. P. Atkinson. 1976. Hereditary angioedema: the clinical syndrome and its management. Ann. Intern. Med. 84: 580.

2. Osler, W. 1888. Hereditary angioneurotic edema. Am. J. Med. Sci. 35: 37.

3. Donaldson, V. H., and R. R. Evans. 1963. A biochemical abnormality in hereditary angioneurotic edema. Am. J. Med. 35: 37.

4. Donaldson, V. H., and F. S. Rosen. 1964. Action of complement in hereditary angioneurotic edema: the role of C'l esterase. J. Clin. Invest. 43: 2204.

5. Levy, L. R., and I. H. Lepow. 1959. Assay and properties of serum inhibitor of Cl-esterase. Proc. Soc. Exp. Biol. Med. 101: 608 .

6. Donaldson, V. H., O. D. Ratnoff, W. Dias Da Silva, et al. 1969. Permeability increasing activity in hereditary angioneurotic edema plasma. II. Mechanism of formation and partial characterization. J. Clin. Invest. 48: 642.

7. Rosen, F. S., P. Charache, J. Pensky, et al. 1965. Hereditary angioneurotic edema: two genetic variants. Science (Wash. D. C.). 148: 957 .

8. Rosen, F. S., C. A. Alper, J. Pensky, et al. 1971. Genetically determined heterogeneity of the $\mathrm{Cl}$ esterase inhibitor in patients with hereditary angioneurotic edema. J. Clin. Invest. 50: 2143.

9. Laurell, A. B., and U. Martensson. 1971. Cl inactivator protein complexed with albumin in plasma from a patient with angioneurotic edema. Eur. J. Immunol. 1: 146.

10. Spaulding, W. B. 1960. Methyltestosterone therapy for 
hereditary episodic edema (hereditary angioneurotic edema). Ann. Intern. Med. 53: 739.

11. Davis, P. J., F. B. Davis, and P. Charache. 1974. Longterm therapy of hereditary angioedema (HAE): preventive management with fluoxymesterone and oxymethalone in severely affected males and females. Johns Hopkins Med. J. 135: 391 .

12. Gelfand, J. A., R. J. Sherins, D. W. Alling, and M. M. Frank. 1976. Treatment of hereditary angioedema with danazol. N. Engl. J. Med. 295: 1444.

13. Gadek, J. E., S. W. Hosea, and M. M. Frank. 1978. The purification and metabolism of $\mathrm{Cl}$ inhibitor and its phenotypic variants. J. Immunol. 120: 1774. (Abstr.)

14. Gigli, I., S. Ruddy, and K. F. Austen. 1968. The stoichiometric measurement of the serum inhibitor of the first component by the inhibition of immune hemolysis. $J$. Immunol. 100: 1154.

15. Avrameas, S., and T. Ternyuck. 1969. The cross-linking of proteins with glutaraldehyde and its use for the preparation of immunoadsorbents. Immunochemistry. 6: 53.

16. Steinbach, M., and R. Audran. 1969. The isolation of IgG from mammalian sera with the aid of caprylic acid. Arch. Biochem. Biophys. 134: 279.

17. Laurell, C. B. 1965. Antigen-antibody crossed electrophoresis. Anal. Biochem. 10: 358.

18. Kueppers, F., and L. F. Black. 1974. State of the art: alpha 1-antitrypsin and its deficiency. Am. Rev. Respir. Dis. 110: 176.

19. Marciniak, E., C. H. Farley, and P. A. DeSimone. 1974. Familial thrombosis due to antithrombin III deficiency. Blood. 43: 219.

20. Shokier, M. H. K. 1973. The genetics of hereditary angioedema: a hypothesis. Clin. Genet. 4: 494.

21. Lachman, P. 1976. The genetics of complement and its deficiencies. An International Symposium on the Nature and Significance of Complement Activation. W. Pollack and P. L. Mollison, editors. A. M. Reiss. 67. 